\title{
Pengaruh Diskon, Kualitas Pelayanan dan Atmosfer Toko terhadap Pembelian Impulsif di Jungkir Balik Eat \& Coffee Sidoarjo
}

\author{
*Mayrine Aulia Faustin, Muslichah ErmaWidiana, Enny Istanti \\ Program Studi Manajemen Fakultas Ekonomi dan Bisnis \\ Universitas Bhayangkara Surabaya, Indonesia
}

\begin{abstract}
Abstrak
DOI: $10.46821 /$ benchmark.v1i2.144

Penelitian ini bertujuan untuk mengetahui pengaruh diskon, kualitas pelayanan dan atmosfer toko terhadap pembelian impulsif di Jungkir Balik Eat \& Coffee Sidoarjo. Penelitian ini menggunakan variabel independen yaitu diskon, kualitas pelayanan dan atmosfer toko. Variabel dependennya adalah pembelian impulsif. Sampel penelitian ini adalah konsumen Jungkir Balik Eat \& Coffee Sidoarjo. Teknik pengambilan sampel dilakukan dengan metode simple random sampling. Pengumpulan data dilakukan dengan penyebaran kuesioner yang diberikan kepada 65 konsumen Jungkir Balik Eat \& Coffee Sidoarjo. Metode analisis dilakukan dengan menggunakan analisis regresi linear berganda. Pengujian hipotesis menggunakan uji statistik F, uji statistik t dan uji dominan. Hasil penelitian ini menunjukkan bahwa diskon, kualitas pelayanan dan atmosfer toko secara simultan berpengaruh positif dan signifikan terhadap pembelian impulsif di Jungkir Balik Eat \& Coffee Sidoarjo. Diskon dan atmosfer toko secara parsial berpengaruh positif dan signifikan terhadap pembelian impulsif di Jungkir Balik Eat \& Coffee Sidoarjo sedangkan kualitas pelayanan secara parsial tidak berpengaruh dan tidak signifikan terhadap pembelian impulsif di Jungkir Balik Eat \& Coffee Sidoarjo. Variabel independen yang berpengaruh dominan terhadap pembelian impulsif di Jungkir Balik Eat \& Coffee Sidoarjo adalah atmosfer toko.
\end{abstract}

Kata kunci : Diskon, Kualitas Pelayanan, Atmosfer Toko dan Pembelian Impulsif

\begin{abstract}
This study was aimed to determine the influence of discounts, service quality and store atmosphere on impulsive purchases in "Jungkir Balik Eat \& Coffee Sidoarjo". This study used independent variables, such as discounts, service quality and store atmosphere. The dependent variable was impulsive purchase. The sample of this study was the consumers of "Jungkir Balik Eat \& Coffee Sidoarjo". The sampling technique was done by simple random sampling method. Data collection was carried out by distributing questionnaires given to 65 consumers "Jungkir Balik Eat \& Coffee Sidoarjo". The analysis method was done by using multiple linear regression analysis. Hypothesis testing used the F statistical test, the t statistical test and the dominant test. The results of this study indicated that discounts, service quality and store atmosphere simultaneously had a positive and significant effect on impulsive purchases in "Jungkir Balik Eat \& Coffee Sidoarjo". Discounts and store atmosphere partially gave positive and significant effect on impulsive purchases in "Jungkir Balik Eat \& Coffee Sidoarjo" while the service quality partially had no effect and was not significant on impulsive purchases in "Jungkir Balik Eat \& Coffee Sidoarjo". The independent variable that had a dominant influence on impulsive purchases in "Jungkir Balik. Eat \& Coffee Sidoarjo" was the store atmosphere.
\end{abstract}

Keywords: Discount, Service Quality, Store Atmosphere, and Impulsive Purchase

*Corresponding Author:

Hal: 66-74

Email: mayrineaulia1998@gmail.com 
Globalisasi di era digital memberikan berbagai kemudahan bagi manusia diberbagai aspek kehidupan. Kemajuan pengetahuan ilmiah dan teknologi yang berskalasi sangat tinggi, mengubah tatanan budaya, sosial, politik dan kehidupan masyarakat dunia begitu cepat (Amir, 2014:1). Seringkali globalisasi malah dapat merubah trend yang beredar itu sendiri, juga mampu merubah gaya hidup, cara pandang, maupun kebiasaan seseorang. Dalam hal ini terjadi proses saling mempengaruhi yang kerap terbentuk saat manusia dengan manusia lainnya bersosialisasi dalam memenuhi kebutuhannya.

Pasar bebas tak hanya mempengaruhi aspek perdagangan antar negara sesama anggota ASEAN, tetapi juga gaya hidup yang berkembang di masyarakatnya. Salah satu pengaruh kebiasaan paling ringan yang masuk adalah menyukai minuman kopi, baik buatan sendiri maupun menikmati kopi di kedai kopi. Banyaknya kedai kopi dan brandbrand asing bermunculan semakin mempersempit kesempatan kedai kopi dan brandbrand kopi lokal Indonesia untuk maju sebagai dampak dari globalisasi dan MEA di Indonesia yang merupakan salah satu anggota ASEAN.

Kebiasaan berkumpul yang biasa disebut "nongkrong" dapat dinilai sebagai salah satu kebutuhan penting manusia sebagai sarana bersosialisasi. "Nongkrong" seringkali dilakukan beramai-ramai meskipun dapat dilakukan seorang diri.Oleh sebab itu kebiasaan "nongkrong" ini membutuhkan tempat-tempat yang nyaman seperti pusat perbelanjaan, mall atau yang paling populer dikalangan remaja saat ini yaitu kedai kopi atau cafe.

Pada penelitian ini penulis memilih kedai kopi Jungkir Balik Eat \& Coffee Sidoarjo sebagai objek penelitian. Memiliki desain modern yang didominasi dengan warna hitam dan kuning membuat kedai kopi ini terlihat mencolok. Ditambah dengan lokasi yang berada di pusat kota Sidoarjo dan di tepi jalan raya membuat para pengendara yang lewat akan dengan mudah mengetahui komplek Bakso Kuto Cak To yang terkesan mewah dan menarik perhatian ini. Namun tak hanya Jungkir Balik Eat \& Coffee Sidoarjo banyak kedai kopi maupun cafe lainnya yang juga menikmati antusiasme masyarakat Sidoarjo terhadap kedai kopi maupun cafe. Beberapa yang terkenal seperti Kober Mie Setan, Kopi Medan, Rolag Kopi, The Little A Coffee Shop, Cyclo Coffee, bahkan Starbucks yang merupakan jaringan kedai kopi global terbesar di dunia turut melebarkan sayapnya di wilayah Sidoarjo. Hal ini tentu patut menjadi perhatian Jungkir Balik Eat \& Coffee Sidoarjo dalam mengupayakan berbagai cara agar dapat meningkatkan daya saingnya agar unggul dalam pasar seperti penerapan berbagai strategi dalam pencapaian tujuan dan target penjualan.

Pembelian impulsif (impulse buying) didefinisikan sebagai tindakan membeli yang sebelumnya tidak diakui secara sadar sebagai hasil dari suatu pertimbangan atau niat membeli sebelum memasuki toko. Dalam definisi yang lain, pembelian impulsif adalah suatu desakan hati yang tiba-tiba dengan penuh kekuatan, bertahan dan tidak direncanakan untuk membeli sesuatu secara langsung, tanpa banyak memperhatikan akibatnya (Utami, 2017:56).Konsumen seringkali mengurangi evaluasi pengetahuan tentang produk, sehingga konsumen membeli secara spontan tanpa mempertimbangkan konsekuensi di masa mendatang (Ratih dan Astiti 2016). Karena hal inilah memperbesar pembelian impulsif yang dilakukan konsumen dapat meningkatkan omset penjualan sehingga tujuan maupun target perusahaan dapat tercapai bahkan terlampaui. Maka dari itu pembelian impulsif merupakan salah satu cara yang dapat ditempuh Jungkir Balik Eat 
$\&$ Coffee sebagai upaya peningkatan daya saingnya ditengah ganasnya persaingan yang sedang dihadapi.

Diskon adalah pengurangan harga langsung terhadap pembelian selama periode waktu tertentu (Abdurrahman dan Sanusi, 2015:119). Dengan adanya diskon yang terpampang akan membangkitkan kesadaran konsumen akan kebutuhannya terhadap produk tersebut sehingga timbul desakan yang kuat untuk membeli produk tersebut dengan segera dan cenderung mengeliminasi pertimbangan-pertimbangan lainnya yang berujung terjadinya pembelian impulsif. Rendahnya frekuensi diskon dilakukan sebagai kegiatan promosi di Jungkir Balik Eat \& Coffee Sidoarjo merupakan permasalahan yang harus diperhatikan dalam upaya mendorong pembelian impulsif oleh konsumen.

Kualitas pelayanan merupakan tingkat keunggulan yang diharapkan dari suatu penyedia layanan dan kemampuan untuk secara konsisten menyediakan tingkat layanan yang unggul untuk memenuhi kebutuhan pelanggan (Suhartanto dkk; 2017:130). Proses yang memakan waktu lama dan terjadi kesalahan pada orderan yang sampai di Jungkir Balik Eat \& Coffee Sidoarjo akan membuat konsumen merasa kecewa dan tidak betah sehingga konsumen akan merasa tidak puas. Kualitas pelayanan yang buruk akan menjadi penghambat terjadinya pembelian impulsif.

Atmosfir toko menurut Levy dan Weitz yang dikutip dalam buku yang berjudul Ritel Pengelolaan dan Pemasaran karya Suhartanto dkk; (2017:43), keseluruhan desain toko yang dibuat agar dapat terciptanya suasana yang menyenangkan bagi pelanggan yang datang ke toko. Selain kejenuhan terhadap warna yang mencolok, papan tanda Jungkir Balik Eat \& Coffee Sidoarjo yang tidak terlihat jelas juga dapat menimbulkan keraguan di benak konsumen untuk melakukan pembelian yang tidak terencana sebelumnya. Area yang terbuka juga dapat mempengaruhi emosi dan persepsi seseorang dalam melakukan pembelian impulsif.

Berdasarkan latar belakang yang telah dijabarkan, penulis tertarik untuk melakukan penelitian dengan judul: "Pengaruh Diskon, Kualitas Pelayanan dan Atmosfer Toko terhadap Pembelian Impulsif di Jungkir Balik Eat \& Coffee Sidoarjo”.

\section{METODE PENELITIAN}

\section{Populasi dan Sampel}

Populasi dari penelitian ini adalah seluruh konsumen Jungkir Balik Eat \& Coffee Sidoarjo yang jumlahnya tidak diketahui secara pasti. Pada penelitian ini peneliti menggunakan teknik pengambilan sampel secara simple random sampling. Random sampling sederhana merupakan teknik pengambilan sampling dimana setiap sampel secara acak (random) diambil sebagai sampel (Ismail, 2018:42).

Roscoe dalam buku Research Methods For Business dalam Sugiyono (2018:90) memberikan saran-saran tentang ukuran sampel untuk penelitian seperti berikut ini.

a. Ukuran sampel yang layak dalam penelitian adalah antara 30 sampai dengan 500 .

b. Bila sampel dibagi dalam kategori (misalnya: pria-wanita, pegawai negeri-swasta dan lain-lain) maka jumlah anggota sampel setiap kategori minimal 30.

c. Bila dalam penelitian akan melakukan analisis dengan multivariate (korelasi atau regresi ganda misalnya), maka jumlah anggota sampel minimal 10 kali dari jumlah variabel yang diteliti. Misalnya variabel penelitiannya ada 5 (independen + dependen), maka jumlah anggota sampel $=10 \times 5=50$. 
d. Untuk penelitian eksperimen yang sederhana, yang menggunakan kelompok eksperimen dan kelompok kontrol, maka jumlah anggota sampel masing-masing antara $10 \mathrm{~s} / \mathrm{d} 20$.

Berdasarkan ketidakpastian jumlah populasi dan teori yang dikemukakan ahli diatas, serta dengan pertimbangan jumlah total variabel yaitu 4 variabel (3 variabel independent dan 1 variabel dependent), maka jumlah minimal anggota sampel yang diambil adalah $4 \times 10=40$ responden.Untuk itu peneliti memutuskan akan mengambil sampel sebanyak 65 responden.Teknik Pengumpulan data pada penelitian ini dilakukan dengan carainterview, penyebaran kuesioner pada responden yaitu 65 konsumen Jungkir Balik Eat \& Coffee Sidoarjo, serta melakukan observasi.

\section{Teknik Pengumpulan Data dan Teknik Analisis}

Teknik Pengumpulan data pada penelitian ini dilakukan dengan carainterview, penyebaran kuesioner pada responden yaitu 65 konsumen Jungkir Balik Eat \& Coffee Sidoarjo, serta melakukan observasi.Penyebaran kuesioner menghasilkan data primer berupa diskon, kualitas pelayanan, atmosfer toko dan pembelian impulsif di Jungkir Balik Eat \& Coffee Sidoarjo. Setelah diperoleh data primer, penelitian ini kemudian didukung oleh data sekunder yang didapat dari studi kepustakaan maupun data dari Jungkir Balik Eat \& Coffee Sidoarjo. Kemudian data yang diperoleh akandianalisis menggunakan analisis regresi linear berganda.

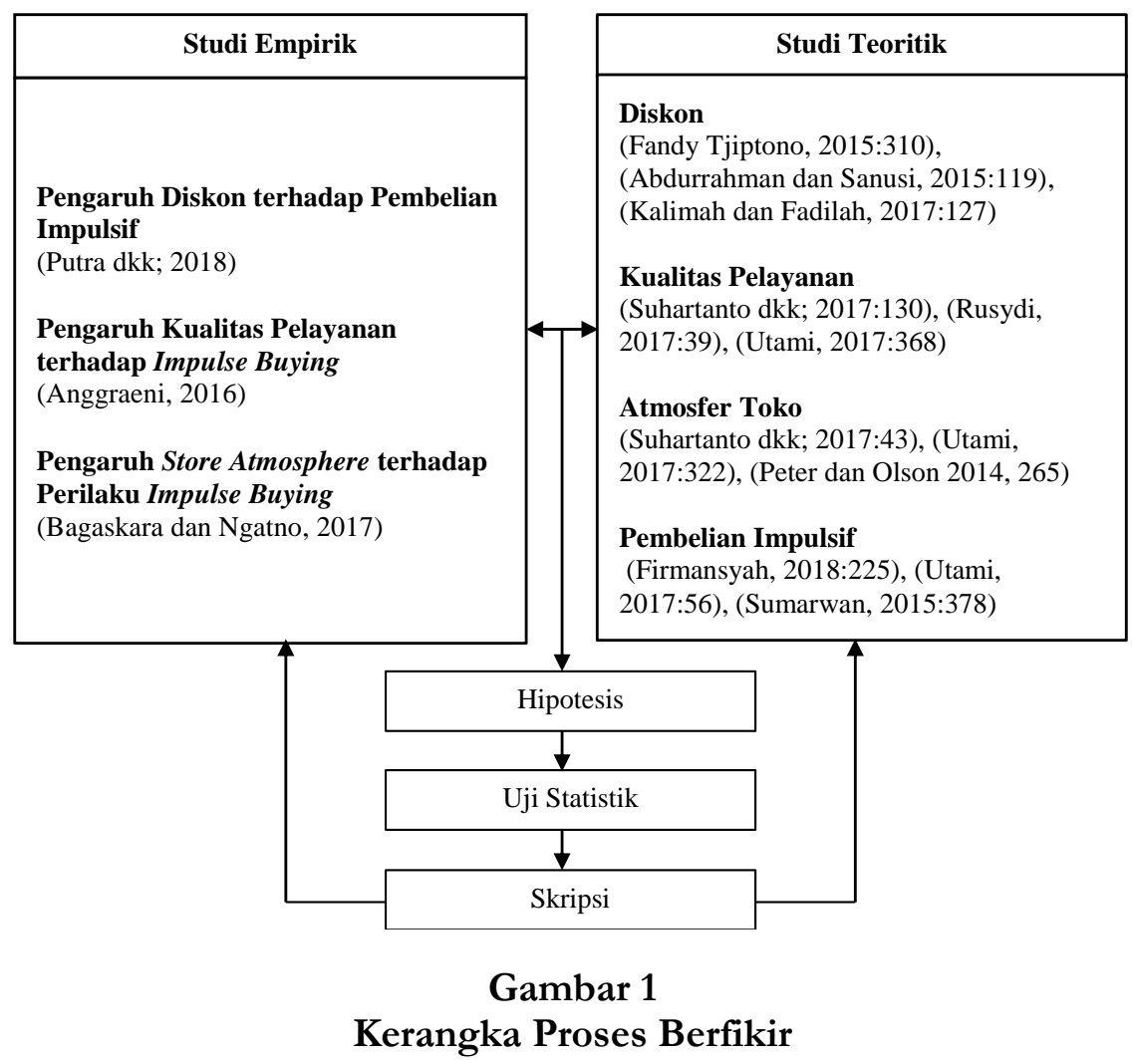




\section{Tabel 1}

Desain Instrumen Penelitian

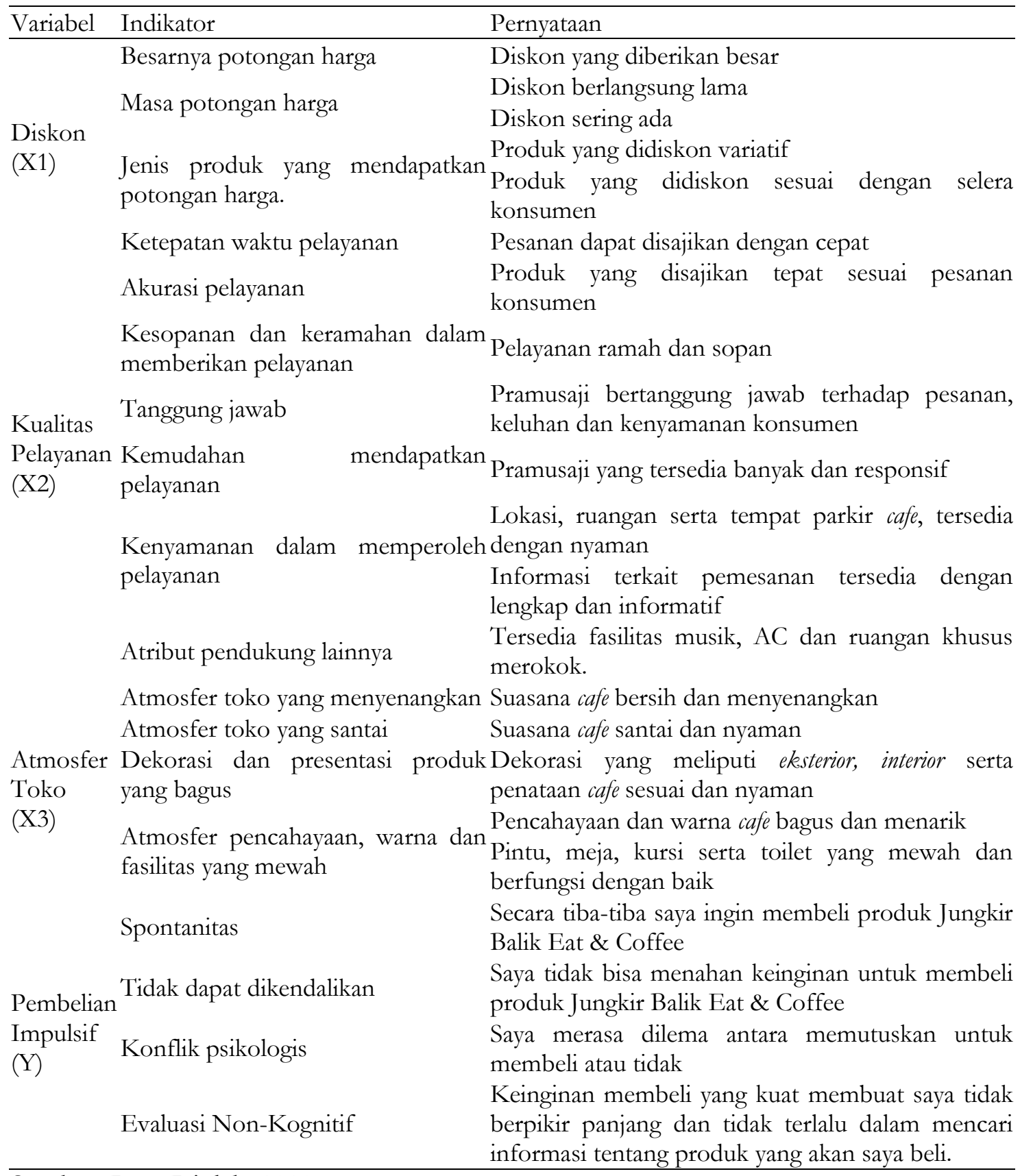

Sumber: Data Diolah, 2020

HASIL ANALISIS DAN PEMBAHASAN

Hasil Analisis Regresi Linear Berganda

Berdasarkan tabel diatas, maka diperoleh persamaan regresi linear berganda sebagai berikut:

$\mathrm{Y}=\mathrm{a}+\mathrm{b} 1 \mathrm{X} 1+\mathrm{b} 2 \mathrm{X} 2+\mathrm{b} 3 \mathrm{X} 3$

$\mathrm{Y}=1,193+0,207 \mathrm{X} 1+0,048 \mathrm{X} 2+0,357 \mathrm{X} 3$ 
Arti dari masing-masing nilai koefisien regresi dalam tabel diatas dapat dijelaskan sebagai berikut:

a. Konstanta (a) $=1,193$

Memiliki arti bahwa jika variabel bebas yaitu diskon, kualitas pelayanan dan atmosfer toko dianggap konstan atau sebesar 0, maka variabel terikat yaitu pembelian impulsif mendapat penilaian sebesar 1,193

b. Koefisien Regresi b1 =0,207

Memiliki arti bahwa jika variabel diskon (X1) ada peningkatan sebesar satu point (persen) maka pembelian impulsif (Y) dapat meningkat sebesar 0,207 dengan anggapan variabel kualitas pelayanan (X2) dan variabel atmosfer toko (X3) dianggap konstan atau sebesar 0 .

c. Koefisien Regresi b2 $=0,048$

Memiliki arti bahwa jika variabel kualitas pelayanan (X2) ada peningkatan sebesar satu point (persen) maka pembelian impulsif $(\mathrm{Y})$ dapat meningkat sebesar 0,048 dengan anggapan variabel diskon (X1) dan variabel atmosfer toko (X3) dianggap konstan atau sebesar 0 .

d. Koefisien Regresi b3 = 0,357

Memiliki arti bahwa jika variabel atmosfer toko (X3) ada peningkatan sebesar satu point (persen) maka pembelian impulsif $(\mathrm{Y})$ dapat meningkat sebesar 0,357 dengan anggapan variabel diskon (X1) dan variabel kualitas pelayanan (X2) dianggap konstan atau sebesar 0 .

\section{Uji F (Simultan)}

Tabel diatas menunjukkan bahwa nilai $\mathrm{F}$ tabel dengan $\mathrm{df}_{1}=3$ dan $\mathrm{df}_{2}=61$, maka diperoleh $\mathrm{F}_{\text {tabel }}=2,76$. Berdasarkan perhitungan menggunakan SPSS diperoleh hasil untuk $\mathrm{F}_{\text {hitung }}$ adalah sebesar 29,607 dengan nilai probabilitas $($ sig $)=0,000$. Sehingga diketahui bahwa $\mathrm{F}_{\text {hitung }}(29,607)>\mathrm{F}_{\text {tabel }}(2,76)$ dan nilai sig lebih kecil dari nilai probabilitas 0,05 atau nilai $0,000<0,05$. Sesuai dengankriteria pengujian maka $\mathrm{Ha}$ diterima. Jadi, dapat disimpulkan bahwa secara simultan variabel bebas yang terdiri dari diskon (X1), kualitas pelayanan (X2) dan atmosfer toko (X3), berpengaruh terhadap variabel terikat yaitu pembelian impulsif $(\mathrm{Y})$.

\section{Tabel 2}

\section{Kuesioner Internal Faktor Analisis Strategi untuk Mengetahui Kekuatan Coefficients $^{a}$}

\begin{tabular}{lcccccc}
\hline \multirow{2}{*}{ Model } & \multicolumn{2}{c}{$\begin{array}{c}\text { Unstandardized } \\
\text { Coefficients }\end{array}$} & $\begin{array}{c}\text { Standardized } \\
\text { Coefficients }\end{array}$ & t & Sig. \\
\cline { 2 - 4 } & B & Std. Error & Beta & & \\
\hline 1 (Constant) & 1.193 & 1.353 & & 0.882 & 0.382 \\
Diskon (X1) & 0.207 & 1.083 & 0.271 & 2.506 & 0.015 \\
Kualitas Pelayanan (X2) & 0.048 & 1.087 & 0.099 & 0.545 & 0.588 \\
Atmosfer Toko (X3) & 0.357 & 1.133 & 0.478 & & 2.684 & 0.009 \\
\hline
\end{tabular}

a. Dependent Variable: Pembelian Impulsif

Sumber: Data Diolah, 2020 


\section{Tabel 3}

ANOVA $^{\mathrm{b}}$

\begin{tabular}{lllllll}
\hline \multicolumn{1}{l}{ Model } & Sum of Squares & Df & Mean Square & F & Sig. \\
\hline \multirow{3}{*}{1} & Regression & 410.288 & 3 & 136.763 & 29.607 & $.000^{\mathrm{a}}$ \\
& Residual & 281.773 & 61 & 4.619 & & \\
\cline { 2 - 5 } & Total & 692.062 & 64 & & & \\
\hline
\end{tabular}

a. Predictors: (Constant), Atmosfer Toko (X3), Diskon (X1), Kualitas Pelayanan (X2)

b. Dependent Variable: Pembelian Impulsif (Y)

Sumber: Data Diolah, 2020

\section{Tabel 4}

\section{Coefficients $^{\mathrm{a}}$}

\begin{tabular}{lccccc}
\hline \multirow{2}{*}{ Model } & \multicolumn{2}{c}{$\begin{array}{c}\text { Unstandardized } \\
\text { Coefficients }\end{array}$} & $\begin{array}{c}\text { Standardized } \\
\text { Coefficients }\end{array}$ & \multirow{2}{*}{$\mathrm{t}$} & \multirow{2}{*}{ Sig. } \\
\cline { 2 - 4 } & $\mathrm{B}$ & Std. Error & Beta & & \\
\hline 1 (Constant) & 1.193 & 1.353 & & 0.882 & 0.382 \\
Diskon (X1) & 0.207 & 1.083 & 0.271 & 2.506 & 0.015 \\
Kualitas Pelayanan (X2) & 0.048 & 1.087 & 0.099 & 0.545 & 0.588 \\
Atmosfer Toko (X3) & 0.357 & 1.133 & 0.478 & 2.684 & 0.009 \\
\hline
\end{tabular}

a. Dependent Variable: Pembelian Impulsif

Sumber: Data Diolah, 2020

\section{Uji t (Parsial)}

Dari uji t dapat diketahui bagaimana variabel bebas secara parsial berpengaruh terhadap variabel terikat. Uji dalam penelitian ini menggunakan taraf signifikansi $5 \%$ atau 0,05 dengan df (n-k)maka diperoleh t tabel $=1,99962$.

a. Diskon (X1)

Berdasarkan hasil pengujian yang dipaparkan dalam tabel, variabel diskon mempunyai pengaruh positif dan signifikan terhadap variabel pembelian impulsif di Jungkir Balik Eat \&Coffee Sidoarjo, yang dapat ditunjukkan dari hasil nilai t hitung $=2,506>\mathrm{t}$ tabel $=1,99962$ dengan $\mathrm{p}$ value $0,015(\mathrm{p}<0,05)$ sehingga Ha diterima.

b. Kualitas Pelayanan (X2)

Berdasarkan hasil pengujian yang dipaparkan dalam tabel, variabel kualitas pelayanan tidak berpengaruh dan tidak signifikan terhadap variabel pembelian impulsif di Jungkir Balik Eat \&Coffee Sidoarjo, yang dapat ditunjukkan dari hasil nilai t hitung = $0,545<\mathrm{t}$ tabel $=1,99962$ dengan $\mathrm{p}$ value $0,588(\mathrm{p}>0,05)$ sehingga Ha ditolak.

c. Atmosfer Toko (X3)

Berdasarkan hasil pengujian yang dipaparkan dalam tabel, variabel atmosfer toko mempunyai pengaruh positif dan signifikan terhadap variabel pembelian impulsif di Jungkir Balik Eat \&Coffee Sidoarjo, yang dapat ditunjukkan dari hasil nilai t hitung $=$ 2,684 $>\mathrm{t}$ tabel $=1,99962$ dengan $\mathrm{p}$ value $0,009(\mathrm{p}<0,05)$ sehingga Ha diterima. 


\begin{tabular}{|c|c|c|c|c|c|}
\hline \multicolumn{6}{|c|}{$\begin{array}{c}\text { Tabel } 5 \\
\text { Hasil Uji Dominan } \\
\text { Coefficients }^{\mathrm{a}}\end{array}$} \\
\hline \multirow[t]{2}{*}{ Model } & \multicolumn{2}{|c|}{$\begin{array}{l}\text { Unstandardized } \\
\text { Coefficients }\end{array}$} & \multirow{2}{*}{$\begin{array}{c}\begin{array}{c}\text { Standardized } \\
\text { Coefficients }\end{array} \\
\text { Beta }\end{array}$} & \multirow[t]{2}{*}{$\mathrm{t}$} & \multirow{2}{*}{ Sig. } \\
\hline & $\mathrm{B}$ & Std. Error & & & \\
\hline 1 (Constant) & 1.193 & 1.353 & & 0.882 & 0.382 \\
\hline Diskon (X1) & 0.207 & 1.083 & 0.271 & 2.506 & 0.015 \\
\hline Kualitas Pelayanan (X2) & 0.048 & 1.087 & 0.099 & 0.545 & 0.588 \\
\hline Atmosfer Toko (X3) & 0.357 & 1.133 & 0.478 & 2.684 & 0.009 \\
\hline
\end{tabular}

a. Dependent Variable: Pembelian Impulsif

Sumber: Data Diolah, 2020

\section{Uji Dominan}

Untuk mengetahui variabel bebas yang berpengaruh dominan terhadap variabel terikat dilakukan dengan cara melihat nilai paling besar dari koefisien regresi yang distandarkan $(\beta)$ atau standardized of coefficient beta diantara variabel bebas yang signifikan yang dapat dilihat dari tabel 5.

Tabel diatas menunjukkan variabel diskon memiliki nilai koefisien regresi beta sebesar 0,271 dan atmosfer toko sebesar 0,478 yang menunjukkan nilai paling besar. Maka hipotesis ketiga yang menyatakan bahwa variabel diskon berpengaruh dominan terhadap pembelian impulsif di Jungkir Balik Eat \& Coffee Sidoarjo ditolak karena variabel bebas yang memiliki pengaruh dominan terhadap variabel pembelian impulsif di Jungkir Balik Eat \& Cofee Sidoarjo adalah atmosfer toko.Harapan konsumen dari atmosfer yang baikadalah terciptanya atmosfer toko yang bersih, nyaman dan menyenangkan, atmosfer yang menarik hati serta mendapat fasilitas yang baik dan mewah. Karena pada akhirnya ketika konsumen melakukan pembelian, konsumen akan menikmati produk yang dibelinya di dalam cafe, tentu hal-hal tersebut sangatlah diharapkan oleh konsumen atas susasana cafe yang mereka kunjungi.

\section{SIMPULAN DAN SARAN}

Variabel diskon, kualitas pelayanan dan atmosfer toko secara simultan berpengaruh signifikan terhadap variabel pembelian Impulsif di Jungkir Balik Eat \& Coffee Sidoarjo. Variabel diskon secara parsial berpengaruh signifikan terhadap pembelian impulsif di Jungkir Balik Eat \& Coffee Sidoarjo. Variabel kualitas pelayanan tidak berpengaruh dan tidak signifikan terhadap pembelian impulsif di Jungkir Balik Eat \& Coffee Sidoarjo. Variabel atmosfer toko secara parsial berpengaruh signifikan terhadap pembelian impulsif di Jungkir Balik Eat \& Coffee Sidoarjo. Diantara ketiga variabel yaitu diskon, kualitas pelayanan dan atmosfer toko variabel yang memiliki pengaruh dominan terhadap pembelian impulsif di Jungkir Balik Eat \& Coffee Sidoarjo adalah variabel atmosfer toko. Jungkir Balik Eat \& Coffee Sidoarjo harus memperbaiki atau meningkatkan ketiga variabel tersebut untuk meningkatkan pembelian impulsif. Periode ketika mengadakan diskon diperpanjang, diskon diadakan lebih sering lagi dengan produk yang diberi diskon lebih variatif. Serta diskon dibuat semenarik mungkin dan konsep yang lebih fresh. Baiknya kualitas pelayanan di Jungkir Balik Eat \& Coffee tetap ditingkatkan lebih baik 
lagi. Agar dapat mendukung terciptanya atmosfer dan citra cafe yang positif. Salah satunya menyediakan fasilitas yang layak seperti music, ruang khusus merokok dan AC. Baiknya Jungkir Balik Eat \& Coffee Sidoarjo tetap berupaya untuk meningkatkan atmosfer yang positif. Terutama dengan memperhatikan kelayakan fasilitas-fasilitas seperti pintu, meja, kursi serta toilet. Selain itu fasilitas yang memiliki tampilan mewah juga diperlukan agar cafe terlihat berkelas. Membuat tata warna yang lebih fresh, simple dan elegant dengan warna kuning dan hitam yang tetap mendominasi. Logo atau papan tanda serta tulisan lebih diperjelas, diperbanyak dan diperbesar. Serta area-area terbuka diberi kanopi. Bagi peneliti lain yang ingin mengkaji fenomena yang serupa, agar mengembangkan lagi menggunakan variabel lain serta memperkuat dengan teori-teori yang lebih banyak dan dan sumber-sumber lainnya yang lebih luas lagi.

\section{DAFTAR PUSTAKA}

Abdurrahman, Nana Herdiana dan Achmad Sanusi. 2015. Manajemen Strategi Pemasaran. Bandung: CV. Pustaka Setia.

Amir, Mohammad Faisal. 2014. Kreativitas dan Inovasi dalam Bisnis: Menggali Potensi Diri Untuk Berkreasi dan Berinovasi. Jakarta: Mitra Wacana Media.

Ismail, Fajri. 2018. Statistika: Untuk Penelitian Pendidikan dan Ilmu-Ilmu Sosial. Jakarta: Prenadamedia Group (Divisi Kencana).

Ratih, I. A. T., \& Astiti, D. P. 2016. Pengaruh motivasi hedonis dan atmosfer toko terhadap pembelian impulsif pada remaja putri di Denpasar. Jurnal Psikologi Udayana, 3(2). Universitas Udayana, Bali. Hal: 209-219.

Sugiyono. 2018. Metode Penelitian: Kuantitatif, Kualitatif, dan R\&D. Bandung: Alfabeta

Suhartanto, Dwi; dkk. 2017. Ritel Pengelolaan dan Pemasaran. Bandung: Alfabeta.

Utami, Christina Whidya. 2017. Manajemen Ritel: Strategi dan Implementasi Operasional Bisnis Ritel Modern di Indonesia, Edisi 3. Jakarta: Salemba Empat. 